\title{
Adaptation of the rubber bandage for safe use as tourniquet
}

\author{
Alfred O. Ogbemudia FWACS* Phillip F. A. Umebese FWACS, FICS* \\ Charles Imarengiaye FWACS** Mobashir Moin FWACS* Anire Bafor M.B, B.S*
}

\begin{abstract}
The safety of the pneumatic tourniquet lies in the fact that the pressure generated beneath it can be determined and is reproducible unlike the rubber bandage toumiquet with subjective and irreproducible tissue pressure. Application of the rubber bandage over the cuff of an aneroid sphygmomanometer enabled direct determination of toumiquet pressure in sixty-four patients with associated low rate of toumiquet related complications. Seventy-eight limbs, in sixty-four patients, were operated using this composite toumiquet and evaluation after surgery as well as out-patients' clinic follow-up for toumiquet complications revealed complications in six out of eight patients in whom the tourniquet time exceeded 120minutes. In conclusion, the inclusion of an aneroid sphygmomanometer to record tourniquet pressure enhanced the safety of the rubber bandage toumiquet in our study and offers an altemative to the pneumatic type in the attairment of bloodless field where the latter is unavailable.
\end{abstract}

\section{INTRODUCTION}

Temporary cessation of circulation in a limb with the aid of a toumiquet to control bleeding and create bloodless field for easy and accurate surgical dissection is an integral part of surgery on the extremity. The pneumatic or rubber bandage tourniquets are the most commonly used types.

KEY WORDS: Safe, Tourniquet, Aneroid sphygmomanometer, Rubber bandage.

aDepartment of Surgery, University of Benin Teaching Hospital, Benin, Nigeria

'Department of Anaesthesia, University of Benin Teaching Hospital, Benin, Nigeria

Correspondence to: Dr Alfred O. Ogbemudia Department of Surgery, University of Benin Teaching Hospital, Benin,

Nigeria E-mail: alfredoghogho@yahoo.com

Phone: 2348023381822

( CMS UNIBEN JMBR 2006; $5(2): 69-74$
The safety of a properly applied pneumatic tourniquet has been well established. ${ }^{1}$ The advantages of the pneumatic tourniquet include accurate and reprootucible control of the circumferential compression pressure applied to a limb. ${ }^{2}$ It is easily inflated and deflated without encroaching on the sterile field. But, cost and the required technical expertise for its maintenance are drawbacks to its use in some hospitals in developing countries. Therefore the rubber bandage tourniquet (RBT) of the Esmarch variety is used routinely in hospitals that do not have pneumatic tourniquets.

The cardinal disadvantage of the RBT is the inability to monitor or record the compressive force applied to the limb when achieving bloodless field. The pressure applied to the limb could easily exceed the safe limits and put the limb at risk of complica- 
tions because the rubber bandage is capable of generating pressures in excess of $1000 \mathrm{mmHg}$ beneath it. ${ }^{3}$ The pressure induced by the rubber bandage increases at a rate of 3 to 4 times the initial pressure when the bandage is stretched after each wrap. ${ }^{4}$

At such extremely high pressure, neurovascular damage becomes likely and makes the use of the RBT relatively unsafe.

We have in the last few years seen the use of the rubber tourniquet by several surgeons of varying experience with attendant tourniquet related complications such as paralysis and skin blisters. We modified the application of the rubber bandage to enable determination of the pressure exerted on the tissues by interposing an aneroid sphygmomanometer cuff between the rubber bandage and the skin and meet our need for safe bloodless field during extremity operations.

The report of our experience with this composite tourniquet is hereby presented.

\section{Patients and method}

This study, a prospective one, was done from March 2002 to February 2005 in the University of Benin Teaching Hospital, Benin City, Nigeria. Sixty-Four patients (30 males and 34 females) make up the cohort. The demographic features of all patients were recorded. Fourteen of the patients had bilateral procedures. All the patients were operated, using a composite tourniquet with a means of ascertaining the pressure exerted on the tissues by the RBT.

Patients undergoing surgery on the limb distal to the proximal three-quarters of the arm or thigh were included in the study. Any sickle cell anaemia patient was excluded from the study. Also excluded were patients in whom dorsalis pedis artery was not palpable or had no posterior tibial pulsation as a result of trauma, diabetes mellitus or peripheral vascular disease.

The device (Figures 1 and 2) comprised of a soft rubber bandage of two metres in length,
15 centimetres in breadth and an aneroid sphygmomanometer with a cuff width of 15 centimetres and a hand-held gauge.

\section{Technique for application}

Prior to application, exsanguination of the limb was done either by compression with a rubber bandage or by elevation of the limb at approximately 45 degrees to the horizontal for 5 minutes. The skin was padded with cotton wool and then the cuff of an aneroid sphygmomanometer was applied round the mid thigh or mid arm, secured and inflated until the manometer read $40 \mathrm{mmHg}$. Thereafter, the rubber bandage was applied external to it (figure 2). The pressure exerted on the cuff by the stretched rubber bandage made the manometer reading to rise with each turn. The maximum tourniquet pressure was individualized. The patient's highest systolic blood pressure in the last 24 hours before induction of anaesthesia was used as baseline systolic blood pressure (BSBP). The tourniquet pressure was raised to 150mmh above the BSBP for lower limbs or $100 \mathrm{mmHg}$ for upper limbs. The number of turns required to attain an effective tourniquet pressure was noted. The time of application and removal of the device was also noted.

The presence of superficial venous distension during skin preparation was noted as evidence of inadequate arterial occlusion. The amount of haemorrhage in the course of surgery was also noted. The maximum allowable tourniquet time was 150minutes. There was no re-application after removal of the RBT.

Each limb was evaluated for the presence of paresis or paralysis, reactionary haemormage, haematoma, compartment syndrome, digital necrosis, and blistering of the skin at the site of application of the tourniquet in the recovery room and later on in the ward at 24 and 48 hours after surgery.

Each patient had individualized postoperative care that included limb elevation, wound 


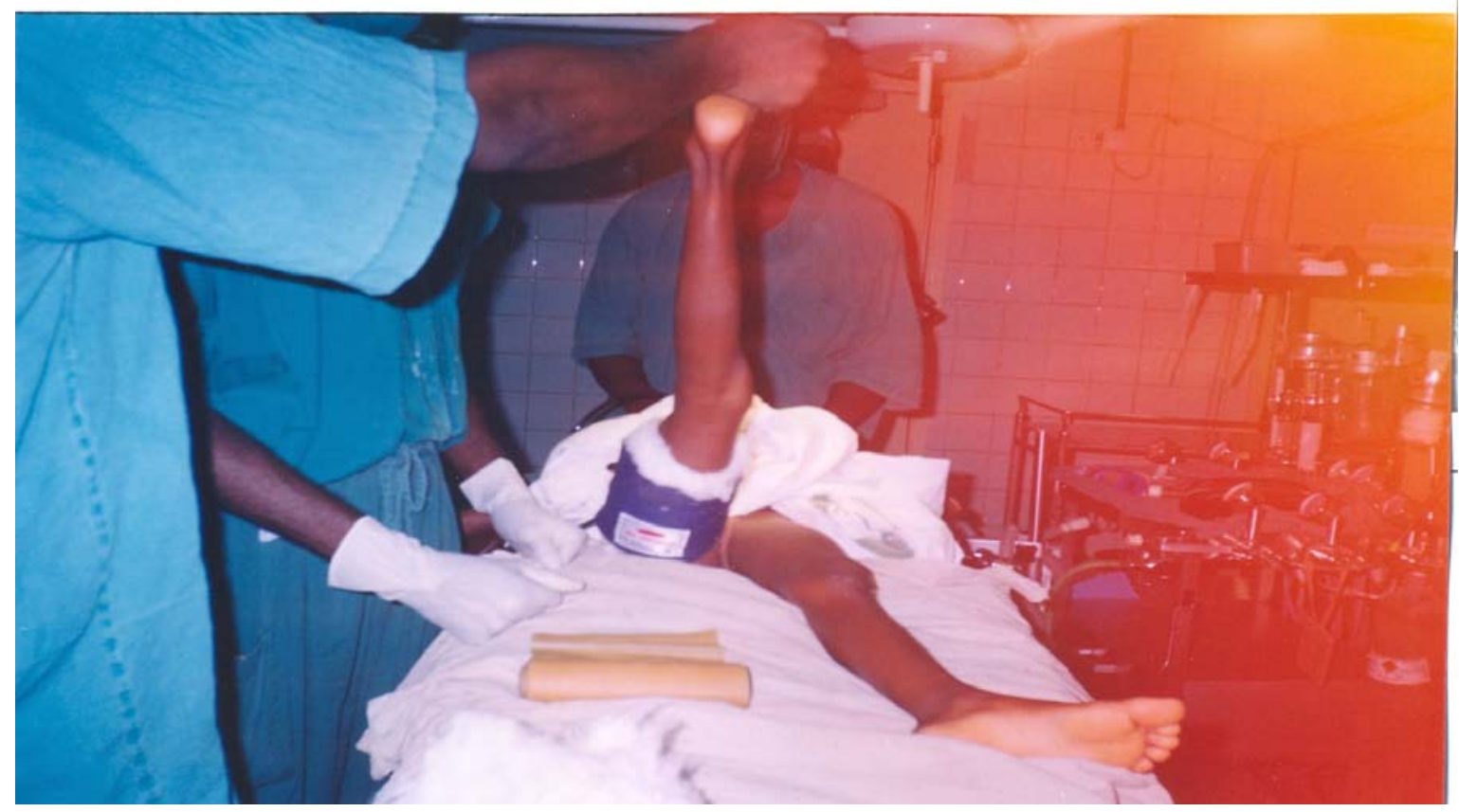

Figure 1: The Esmarch bandage and the aneroid sphygmomanometer before complete application

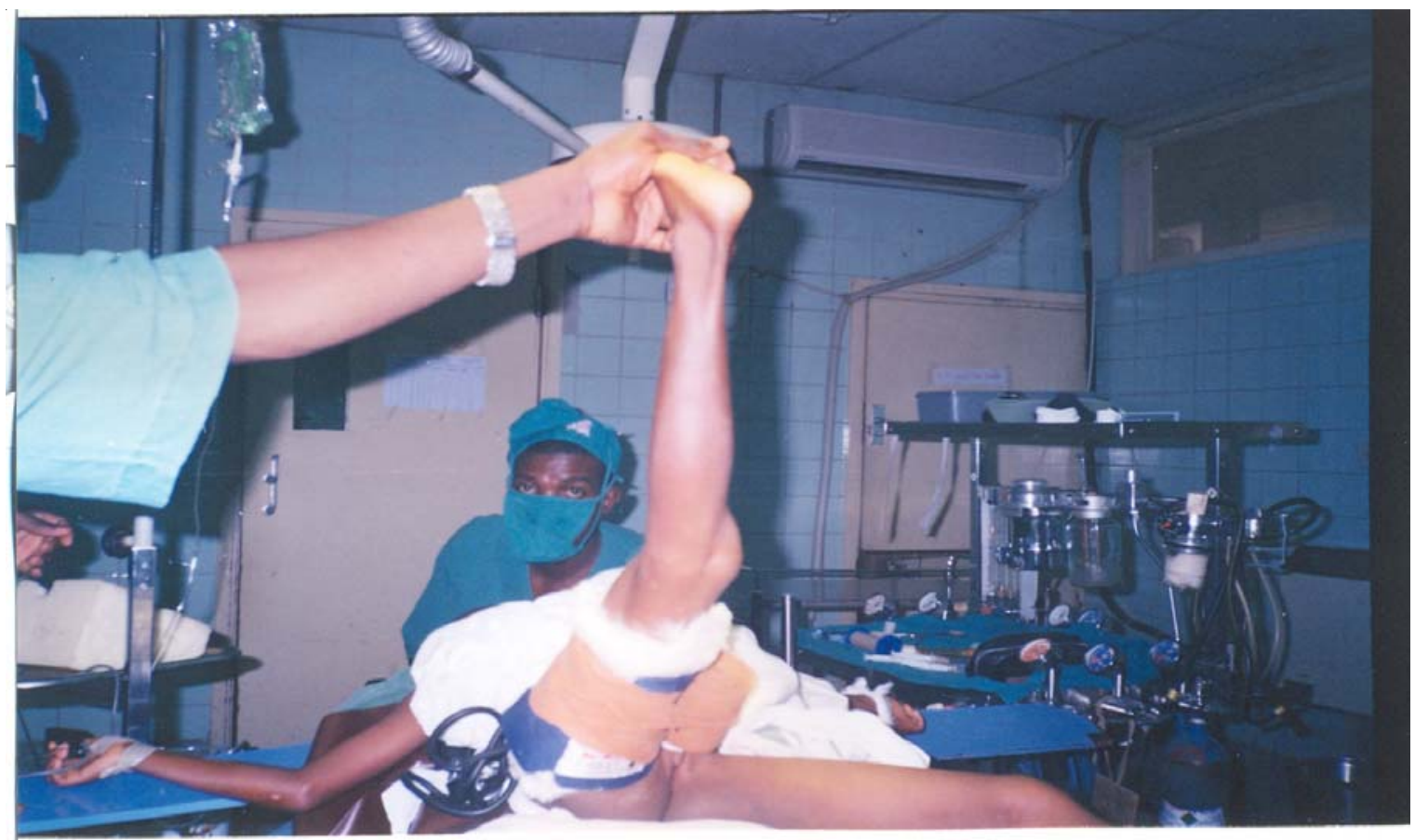

Figure 2: The device after application (Ready for skin preparation) 
care, antibiotics and analgesics. Follow-up in the out-patients' clinic was continued for six months to detect the presence of late posttourniquet syndrome.

\section{Results}

Fourteen patients had bilateral procedures (13 involving the lower limbs and 1 in the upper limb). The mean age of the patients was $20.59 \pm 16.04$ years with standard error of 1.82 (range 2 to 70 years) (Table 1 ). The mean tourniquet time was $74.23 \pm 31.56$ minutes with standard error of 3.57 (Range 25 to 145 minutes). In eight limbs (10.3\%) the tourniquet was removed before completion of surgery to avoid risks associated with prolonged tourniquet time.

In 70 limbs tourniquet time was equal to or less than 120minutes, and had no problem. Eight patients had the tourniquet on for more than 120minutes and six of them suffered reactionary haemorrhage. One of these six had a tourniquet time of 145minutes and besides the reactionary haemorrhage, had wound haematoma and compartment syndrome. In another patient reactionary haemorrhage necessitated transfusion of two pints of whole blood. The rest 4 of the six patients who suffered reactionary haemorrhage had uneventful resolution following elevation and pressure dressings. The mean estimated blood loss was $145.51 \pm 198.01 \mathrm{mls}$. In $59 \%$ of patients 4 turns of the rubber tourniquet was sufficient to attain the desired tourniquet pressure while 3 and 5 turns respectively were required in $2.6 \%$ and $38.5 \%$ of patients. The mean number of turns was $4.36 \pm 0.53$. There was no case of dissatisfactory toumiquet effect or loss of tourniquet pressure in the course of surgery in all the patients.

No case of digital necrosis, nerve palsy, or blistering of the skin was recorded.

\section{Discussion}

This study indicates that a composite tourniquet consisting of a rubber bandage and an aneroid sphygmomanometer is safe and provides bloodless field. It has shown that it is possible to determine the tourniquet pressure of a rubber bandage. This offers solution to the problem of indeterminable underlying pressure which is a reason for the poor safety margin of the rubber bandage tourniquet and tends to have reduced the potential dangers in its use.

Excessive or insufficient pressure and application for too long are factors that may increase the risk of tourniquet related complications. ${ }^{5}$ The rubber tourniquet in its unmodified form could be associated with excessive or inadequate pressure which could cause direct damage to nerves in particular. Solomon, Warwick and Nayagam, condemned the use of the rubber bandage for bloodless field surgery on account of the inability to determine the pressure beneath it. ${ }^{6}$

However, some authors have reported safe use of esmarch tourniquets of 3 or 4 inches width; if the number of turn is limited to 3 or $4 .^{7}$ How much force to apply as each turn of

Table 1: Age and Sex distribution of patients

\begin{tabular}{lcccc}
\hline Age range & Males & Females & Total & $\%$ \\
\hline $01-10$ & 8 & 11 & 19 & 29.7 \\
$11-20$ & 5 & 10 & 15 & 23.4 \\
$21-30$ & 6 & 7 & 13 & 20.3 \\
$31-40$ & 7 & 1 & 8 & 12.5 \\
$41-50$ & 1 & 2 & 3 & 4.7 \\
$51-60$ & 2 & 2 & 4 & 3.3 \\
$61-70$ & 1 & 1 & 2 & 3.1 \\
\hline Total & 30 & 34 & 64 & 100 \\
\hline
\end{tabular}


Adaptation of the rubber bandage for safe use as tourniquet 73

the rubber tourniquet is made remains subjective and makes the eventual tourniquet pressure difficult to ascertain.

Practicable and clinically suitable objective estimate of the pressure applied to the tissues during use of the RBT is necessary for enhancing its safety. The incorporation of an aneroid sphygmomanometer provided a means of determining the pressure applied to tissues underneath the rubber tourniquet with the effect of making the rubber bandage toumiquet safer.

The safety profile of this adaptation of the rubber bandage is similar to the evidence in the literature. ${ }^{2,487}$ Furthermore, the ability to demonstrate the underlying pressure adds value to the quality of existing evidence of rubber tourniquet safety.

The choice of maximum tourniquet pressure in this study was predicated on the work of Solomon et $a l^{6}$ who recommended tourniquet pressure of $150 \mathrm{mmHg}$ and $80-$ $100 \mathrm{mmHg}$ above the systolic blood pressure for lower and upper limbs respectively. ${ }^{6}$ Although the minimum cuff pressure required to maintain a bloodless field should be the tourniquet pressure in order to reduce the incidence of tourniquet related complications, ${ }^{8}$ we decided to use the recommendations of Solomon et al because of ease of application. A tourniquet time of 3 hours was considered the upper limit of safety by Solomon et a ${ }^{6}$ while another opinion suggested that tourniquet time of less than 2 hours improves the safety of tourniquets. ${ }^{9}$ The choice of 150 minutes as the maximum tourniquet time in this study was based on the simple average of these positions. This study shows that 150 minutes is within the safety limits of toumiquet time and that exceeding 120 minutes contributes significantly to post tourniquet morbidity because three-quarters of patients who had the tourniquet on for more than 120minutes had complications while no case was recorded at 120 minutes and below. The observed complications were reactionary haemorrhage, haematoma and compartment syndrome. Complications like tourniquet paralysis, blistering of the skin, digital necrosis, and primary haemorrhage due to loss of tourniquet effect were not seen in this study.

There was premature removal of the tourniquet before completion of surgery in 10.3\% of limbs. Application of the rubber tourniquet before skin preparation and draping could have contributed to this observation because operation site preparation adds to the total operation time and shortens effective operation time whilst using a rubber tourniquet.

This adaptation of the RBT is affordable and easy to assemble.

The result of this study indicates that this device provided bloodless surgical field with acceptable complication rate. Incorporating an aneroid sphygmomanometer in the use of the rubber bandage for tourniquet effect in limb operations enabled us to determine the pressure applied to the tissues.

We believe that this composite tourniquet of rubber bandage and aneroid sphygmomanometer should be of value in field surgery and in hospitals that may be unable to procure and/or maintain pneumatic tourniquets.

\section{References}

1 Reid H. S; Camp R. A; Jacob W. H. Tourniquet haemostasis: a clinical study. Clinical Orthopaedics, 1983; 177: 230-234.

2 Lichtenfeld N. S. The pneumatic ankle tourniquet with ankle block anaesthesia for foot surgery. Foot Ankle (US), 1992; 13: 334-9.

3. McLaren A.C; Rorabek C. H. The pressure distribution under tourniquets. J Bone Joint Surg Am(US), 1985; 67: 433-8.

4 Abraham E; Amirouche F. M. Pressure controlled esmarch bandage used as tourniquet. Foot Ankle Int. (US), 2000; 21: 686-9. 
74 Journal of Medicine and Biomedical Research

5. Crenshaw A.H. Surgical Techniques and Approaches. In Canale S.T. editor. Campbell's operative orthopaedics. 9th edition. Missouri, Mosby, 1998, 30-31.

6. Solomon L; Warwick D; Nayagam S. Apley's system of orthopaedics and fractures. London, Arnold, 2001, 255-6.

7. Biehl E. C; Morgan J.M; Wagner F. W; Gabriel R. A. The safety of the esmarch tourniquet. Foot Ankle (US), 1993; 14: 278-83.
8. McEwen J. A; Kelly D. L; Jardanowski T; Inkpen K. Tourniquet safety in lower leg applications. Orthop. Nursing (United States), 2002; 21: 55-62.

9. Warwick D.J. Wrist and hand. In Russell R. C. G; Williams N. S; Bulstrode C. J. K. editors, Bailey and Love's short practice of surgery. 23rd edition. London, Arnold, 2000, 478. 